\title{
Research on Automated Project Performance Control: An Update
}

\author{
Ronie Navon
}

Associate Professor, Head, Construction Management \& Economics - National Building Research Institute (NBRI), Faculty of Civil \& Environmental Engineering, Technion City, 32000 Haifa, Israel. E-mail: ronie@technion.ac.il.

\section{Introduction}

Project performance control normally requires massive manual data collection - the more detailed the required control information, the more labor intensive the data collection must be. Hence, the cost of collecting the data and generating the information is high and the quality, integrity and real-time availability are low. Our proposition, for more than a decade, has been to either automate the data collection using advanced technologies, or use existing tools (e.g. daily site report - DSR) to minimize the data collection. This was done in a variety of areas: labor tracking; earthmoving operations; daily-site-report based control; change management tool; materials management and control; safety control; and company level monitoring - all are briefly reported in this extended abstract.

\section{Labor tracking}

Labor is one of the most significant resources in construction projects, hence controlling this resource can contribute meaningfully to the efficiency of managing the projects, both in terms of cost and progress. Our approach to labor tracking was to automate the data collection using automated location measurement technologies and to convert these locations into the desired information. The algorithm, developed for this conversion, automatically determines what activity is done at any given time (Goldschmidt and Navon 1996; Navon and Goldschmidt 1999; Navon and Goldschmidt 2003a; Navon and Goldschmidt 2003b). The algorithm was tested on site in a series of experiments to determine the feasibility of implementing it.

We are currently conducting simulated experiments of RFID technology to replace the location measurement technology. Instead of measuring the locations of the workers and associating them to building elements this algorithm determines which building element is worked on at each given time, based on RFID measurement.

\section{Earthmoving Operations}

The same principles, of automated location measurement and its conversion into control information, were used here. A model that uses location data measured with a GPS was developed and tested on site (Navon et al. 2004; Navon and Shpatnitsky 2005; Navon and Shpatnitsky 2006; Navon et al. 2002). This model required manual intervention at the end of each measurement day, which led to the next stage of the research: the dynamic work envelope (DWE) approach. In the DWE approach, instead of associating locations to activities by predetermining work sections, the algorithm determines the work envelopes dynamically during its operation, according to the measured locations. This approach is fully automated.

\section{Daily-Site-Report Based control tool}

The daily site report (DSR) logs most of the major events occurring in a construction site on a daily basis. The document is approved and signed both by the contractor and the owner. Hence, the DSR is a reliable and accurate source of data, capable of being available almost in real-time. In spite of this, it is very rarely used to control the project - it is mostly used for litigation purposes. The data in the DSR is still normally handwritten, which makes it hard to use even for litigation purposes because it is often illegible, unstructured and is not searchable.

We have developed a model, which uses an electronic format of the DSR, thus enabling the extraction of relevant data and their processing in order to generate real-time control information. The model provides an 
as-made schedule compared to the planned one (Navon and Haskaya 2007). In addition, the model calculates and compares the planned usage of resources to the ones actually consumed on site.

\section{Change Management and Control Tool}

Changes made in construction projects during their design and execution are a major cause for delays, cost overruns and deviations from performance requirements. The impact of changes often becomes clear only after their implementation in the project. At that stage it is difficult to make adjustments or consider alternatives. A timely recognition, by the project team, of the implications of proposed changes can lead to a reconsideration of the changes, so that the completed project will still meet the client's objectives.

We are developing a model that facilitates automatic identification of the possible consequences of changes when they are first proposed, prior to their implementation in the design and planning of the project (Isaac and Navon 2008; Isaac and Navon 2009). A graph-based approach is used in order to identify the impact of changes on the primary client objectives of cost, schedule and performance. Further research is being undertaken to develop the model's ability to quantify the extent of the change impact through the use of stochastic tools.

\section{Materials Management and Control}

Materials contribute a very significant percentage of the cost of construction projects. Workers are often idle, waiting for unavailable materials. Hence, efficient materials management and control can contribute not only to reduced materials waste, but also to increased productivity.

We have developed a model, which deals with materials purchasing, their delivery to the site and their dispatching for use in the building. The model generates reports and alerts - the reports include a list of all the materials needed in the project, a list of materials to be ordered, a cumulative list of materials flow, list of actually used materials vs. the planned ones and dead inventory, etc. The alerts include purchase orders (PO) not confirmed by the supplier, a list of materials that should have been ordered, but were not, a list of materials that were expected but were not supplied, materials arriving to the site which are incompatible with the PO, and the deviation between planned and actual quantities (Navon and Berkovich 2005; Navon and Berkovich 2006).

\section{Safety Control}

Even though fall from height is the number one risk factor in lethal accidents in construction, many of these accidents could have been avoided if the right preventive measures had been taken in time. The most common preventive measures are guardrails. The aim of our research was to develop an automated model that monitors guardrails in buildings under construction (Navon and Kolton 2006a; Navon and Kolton 2006b). The model identifies the activities associated with the risk of falling from heights and the areas where these activities are scheduled to be performed. Accordingly, the model plans the protective measures, namely the guardrails. The model follows up the existing guardrails and constantly compares their locations and lengths to the planned ones. Based on this comparison, the model issues warnings whenever guardrails are missing, or temporarily removed.

\section{Company Level Monitoring}

Financial ratios (FR) are useful indicators of a company's performance. Most ratios can be calculated from the information provided by the financial statements. FR can be used to analyze trends and to compare the company's financials to those of other companies. There are more than $25 \mathrm{FR}$, but their importance changes according to the type of industry, the characteristics of the company and the country that the company operates in. Limited research was done to identify the most relevant FR for the construction industry.

We interviewed financial managers of construction companies and identified five FR, which are most pertinent to construction companies: Net Income/ Equity; Equity/Total Assets; Operating Profit/Total Sales; Operating Profit/Interest Expense; and Financial Depth/EBITDA Net. As a result of the interviews, we also determined which values of the FR indicate a financially sound company ("desired values"). Then we 
analyzed the financial statements of 18 public construction companies and compared the actual values of their FR to the "desired values". These "desired values" are probably more pertinent to the Israeli construction industry.

\section{Conclusions}

Our research, in a variety of areas, shows that data collection for real-time control can be reduced dramatically. As a result, the control information is less expensive to generate, more accurate, of a higher level of integrity and less error prone.

\section{Acknowledgments}

This research was partly supported by THE ISRAEL SCIENCE FOUNDATION (grant No. 444/05). This support is gratefully acknowledged. I would like to thank my colleagues for their invaluable contributions to the research described in this extended abstract. They are O. Berkovich, Y. Doytsher, E. Goldschmidt, I. Haskaya, S. Isaac, S. Khoury, O. Kolton, I. Paz-Chen, Y. Shpatnitsky, and A. Warszawski.

\section{References}

[1] Goldschmidt, E., and Navon, R. "Automated Real-Time Manpower Productivity Control." The Eighth International Symposium on Organization \& Management of Construction, Glasgow, UK, 199-205.

[2] Isaac, S., and Navon, R. (2008). "Feasibility Study of an Automated Tool for Identifying the Implications of Changes in Construction Projects." Journal of Construction Engineering and Management, ASCE, 134(2): 139-145.

[3] Isaac, S., and Navon, R. (2009). "Modeling Construction Projects as a Basis for Change Control." Automation in Construction: (scheduled).

[4] Navon, R., and Berkovich, O. (2005). "Development and On Site Evaluation of an Automated Materials Management and Control Model." Journal of Construction Engineering and Management, ASCE, 131(2): 1328-1336.

[5] Navon, R., and Berkovich, O. (2006). "An Automated Model for Materials Management and Control." Construction Management and Economics, 24(6): 635-646.

[6] Navon, R., and Goldschmidt, E. "Automated Data Acquisition for On-Site Control." 16th IAARC/IFAC/IEEE International Symposium on Automation and Robotics in Construction (ISARC'99), Madrid (Spain), 681-686.

[7] Navon, R., and Goldschmidt, E. (2003a). "Can Labor Inputs be Measured and Controlled Automatically?" Journal of Construction Engineering and Management, ASCE, 129(4): 437-445.

[8] Navon, R., and Goldschmidt, E. (2003b). "Monitoring Labor Inputs: Automated-Data-Collection Model and Enabling Technologies." Automation in Construction, 12(2): 185-199.

[9] Navon, R., Goldschmidt, E., and Shpatnitsky, Y. (2004). "A Concept Proving Prototype of Automated Earthmoving Control." Automation in Construction, 13(2): 225-239.

[10] Navon, R., and Haskaya, I. (2007). "Is detailed progress monitoring possible without designated manual data collection?" Construction Management and Economics, 24(12): 1225-1229.

[11] Navon, R., and Kolton, O. (2006a). "Algorithms for Automated Monitoring and Control of Fall Hazards." Journal of Computing in Civil Engineering, ASCE, Submitted.

[12] Navon, R., and Kolton, O. (2006b). "A Model for Automated Monitoring of Fall Hazards in Building Construction." Journal of Construction Engineering and Management, ASCE, Accepted.

[13] Navon, R., and Shpatnitsky, Y. (2005). "Field Experiments in Automated Monitoring of Road Construction." Journal of Construction Engineering and Management, ASCE, 131(4): 487-493.

[14] Navon, R., and Shpatnitsky, Y. (2006). "A Model for Automated Monitoring of Road Construction." Construction Management and Economics, 23(9): 941-951.

[15] Navon, R., Shpatnitsky, Y., and Goldschmidt, E. "Model for Automated Road-Construction Control." Nineteenth International Symposium on Automation and Robotics in Construction, 425-430. 